\title{
Ionospheric Effects of the March 13, 1989 Magnetic Storm at Sub-Auroral Region
}

\author{
Ruiyuan $\mathrm{LiU}^{1}$, Shunlin $\mathrm{LIU}^{1}$, Bo WEN ${ }^{2}$, and Changfa LiU ${ }^{3}$ \\ ${ }^{1}$ Polar Research Institute of China, Shanghai 200129, China \\ ${ }^{2}$ China Research Institute of Radiowave Propagation, Xinxiang 453003, Henan. China \\ ${ }^{3}$ Institute of Geophysics, Academia Sinica, Beijing 100101, China
}

(Received November 25, 1994; Revised May 18, 1995; Accepted December 13, 1995)

\begin{abstract}
Ionograms and magnetograms at Great Wall (62 $\left.{ }^{\circ} 13^{\prime} \mathrm{S}, 58^{\circ} 58^{\prime} \mathrm{W}\right)$, Antarctica, were used to study the ionospheric effects of the March 13, 1989 magnetic storm in sub-auroral locations. The virtual height of the $F$ region $\left(h^{\prime} F\right)$ increased and the critical frequency $\left(f_{o} F_{2}\right)$ decreased rapidly just after the storm sudden commencement (SSC). Then the spread $F$ appeared and lasted about five hours. During the main phase of the magnetic storm the ionosphere encountered severe absorptions, but large enhancements in $h^{\prime} F$ and associated depressions in $f_{0} F_{2}$ sometimes were still observed. On the second and third nights after the SSC auroral type sporadic $E$ and night $E$ layers were observed, showing peak electron densities as high as $7.5 \times 10^{5} \mathrm{el} \mathrm{cm}^{-3}$. The causes of these phenomena are discussed. Behaviours of $h^{\prime} F$ and $f_{0} F_{2}$ from four ionosonde stations in the same longitude sector (Great Wall, Port Stanley, Cachoeira Paulista and Fortaleza) show that the higher the station's latitude is, the more severe absorptions occur, and the longer the depressions of $f_{o} F_{2}$ last.
\end{abstract}

\section{Introduction}

The great magnetic storm, which began with storm sudden commencement (SSC) at 0127 UT on March 13, 1989 and was the second largest one on the record since 1932, caused serious consequence of the loss of power for nine hours in Quebec, Canada but presented a good opportunity to study the responses of the solar-terrestrial system. Several papers have been published for the March 13,1989 magnetic storm, dealing with the ionospheric effects, some of which are concerned mainly with a localized geographic region (Batista et al., 1991; Huang and Cheng, 1991; Lakshmi et al., 1991), the others are concerned with the global behavior (Hajkowicz, 1991; Yeh and Lin, 1992). In this paper intensive ionograms and magnetograms at Great Wall station $\left(62^{\circ} 13^{\prime} \mathrm{S}, 58^{\circ} 58^{\prime} \mathrm{W}\right)$, Antarctica are used to study the sub-auroral ionospheric effects of the March 13, 1989 magnetic storm, and the comparisons with the data from other ionosonde stations in the same longitude sector are made. The cause of these phenomena are discussed.

\section{Observations}

Ionograms and magnetograms used in this study were obtained using an ionosonde and a magnetometer at Great Wall, Antarctica, which is located in the sub-auroral latitudes with the geomagnetic coordinates of $50.6^{\circ} \mathrm{S}$ and $7.4^{\circ}$ and the McIlwain's parameter $L$ equal to 2.1 . The local time is equal to the universal time minus 4 hours.

Figure 1(b) gives the variation in the horizontal component of the Earth's magnetic field $(\Delta H)$ recorded at Great Wall. The $H$ component showed a typical quiet time behavior on March 12 , until the storm onset at 2127 LT on March 12 with a sudden commencement. After the sharp increase the $H$ component started decreasing rapidly until 2300 LT. During March 13, the main phase of the magnetic storm was observed with large fluctuations superimposed until $1900 \mathrm{LT}$ when the magnetometer became saturated. Unfortunately, the discontinuity in the record occurred until 0845 LT on March 14. Part of the recovery phase were missed and the left one was also characterized by many fluctuations in the geomagnetic field 
Table 1. Characteristics of the March 13, 1989 magnetic storm observed at the Greut Wall, Antarctica.

\begin{tabular}{|c|c|c|c|c|c|c|c|c|c|c|c|c|}
\hline \multicolumn{2}{|c|}{ Storm time (UT) } & \multirow[t]{2}{*}{ Type } & \multicolumn{3}{|c|}{ Amplitude of SSC (nT) } & \multirow{2}{*}{$\begin{array}{l}\text { Degree of } \\
\text { activity }\end{array}$} & \multicolumn{2}{|c|}{ Maximal activity of } & \multirow{2}{*}{$\begin{aligned} K \text { scale } \\
K \text { index }\end{aligned}$} & \multicolumn{3}{|c|}{ Range (nT) } \\
\hline Beginning & Ending & & $D$ & $H$ & $Z$ & & Date & 3-hour period & & $D$ & $H$ & $Z$ \\
\hline 0127, March 13 & 2200, March 15 & $\mathrm{SC}^{*}$ & 24.0 & 62.5 & 42.0 & $\mathrm{~s}$ & 14 & 1 & 9 & $>260$ & $>750$ & $>270$ \\
\hline
\end{tabular}
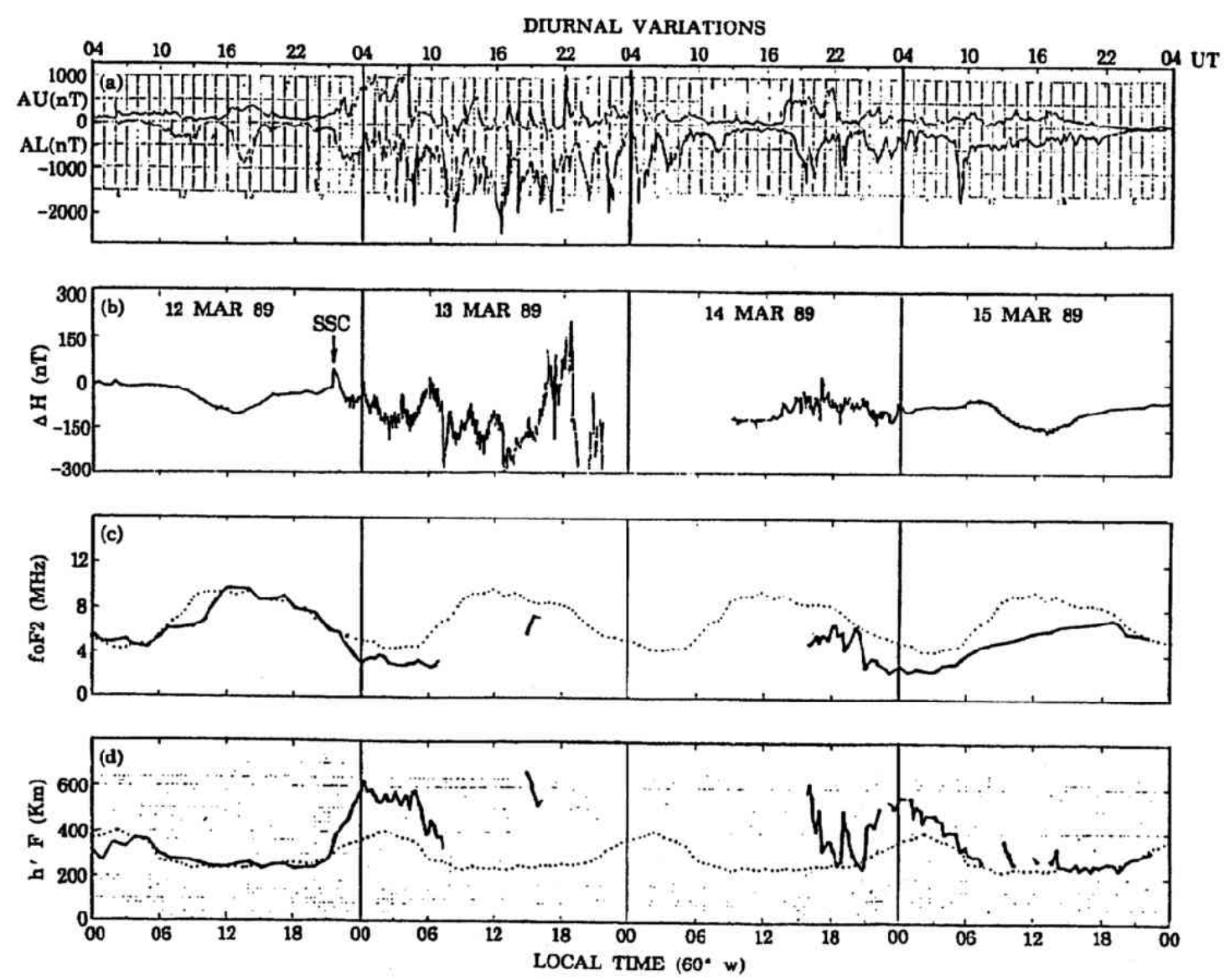

Fig. 1. Diurnal variations in the geomagnetic and ionospheric parameters for the period of March 12-15, 1989 at Great Wall. (a) Auroral electrojet indices; (b) horizontal component of the magnetic field $(\Delta H)$; (c) and (d) $f_{o} F_{2}$ and $h^{\prime} F$ (solid line), and monthly median curve (dotted line).

$H$ component. It is interesting that the negative excursions of the $H$ component (2300 LT on March 12, $0230,0400,0715,1100,1300,1700,2000 \mathrm{LT}$ on March 13 and 1530, 1630, 1830, 2150, 2300 LT on March 14) were almost all in phase with the extreme negative variations on the auroral electrojet index $A L$ in Fig. 1(a), together with the $A U$ index. It demonstrated that the negative excursions of the $H$ component and the auroral substorm occurred simultaneously. The $H$ component of geomagnetic field became flat and steady on March 15, though sometimes had small fluctuations. The characteristics of the March 13 geomagnetic 
storm observed at Great Wall are listed in Table 1.

Figures 1(c) and 1(d) show the critical frequency of the $F$-region, $f_{o} F_{2}$, and the virtual height of the $F$-region, $h^{\prime} F$, as measured by ionosonde operating every 15 minutes at Great Wall. $f_{o} F_{2}$ and $h^{\prime} F$ followed the monthly median values very closely, showing a normal quiet time behavior until the storm onset at 2127 LT on March 12 with a sudden commencement. Just after the SSC, $f_{o} F_{2}$ decreased and $h$ ' $F$ increased rapidly. At $0015 \mathrm{LT}$ on March $13 h^{\prime} F$ had his maximum of $635 \mathrm{~km}$, about $300 \mathrm{~km}$ higher than the corresponding median value. During the main phase of the magnetic storm, the ionosphere encountered severe absorptions. Comparing the monthly median curves shown on Figs. 1(c) and 1(d), the main features of the ionospheric response are as following. During March 13-14, $h^{\prime} F$ remained above the monthly median level almost all the time, only after sunrise on March $15 \mathrm{did} h^{\prime} F$ recover to the undisturbed values. Associated depletions in $f_{o} F_{2}$ were also observed and even lasted longer till $2000 \mathrm{LT}$ on March 15 . Another feature in $F$-region is that from $1600 \mathrm{LT}$ to $2400 \mathrm{LT}$ on March $14 f_{o} F_{2}$ and $h^{\prime} F$ showed wavelike oscillations in opposite phase with periods increasing gradually from half an hour at the start to 2 hours at the end.

The spread $F$ occurred on ionograms at Great Wall, Antarctica with starting time at $2330 \mathrm{LT}$ on March 12, about two hours after the SSC and ended at $0415 \mathrm{LT}$ on March 13. On the second night, the night of $13 / 14$, no F-trace was observed because of high absorptions. On the third night weak spread $F$ was found sometimes from 2115 LT to 2145 LT on March 14 and from 0100 LT to 0115 LT on March 15.

Auroral type sporadic $E$ and night $E$ layers were observed on the second and third nights after the SSC.
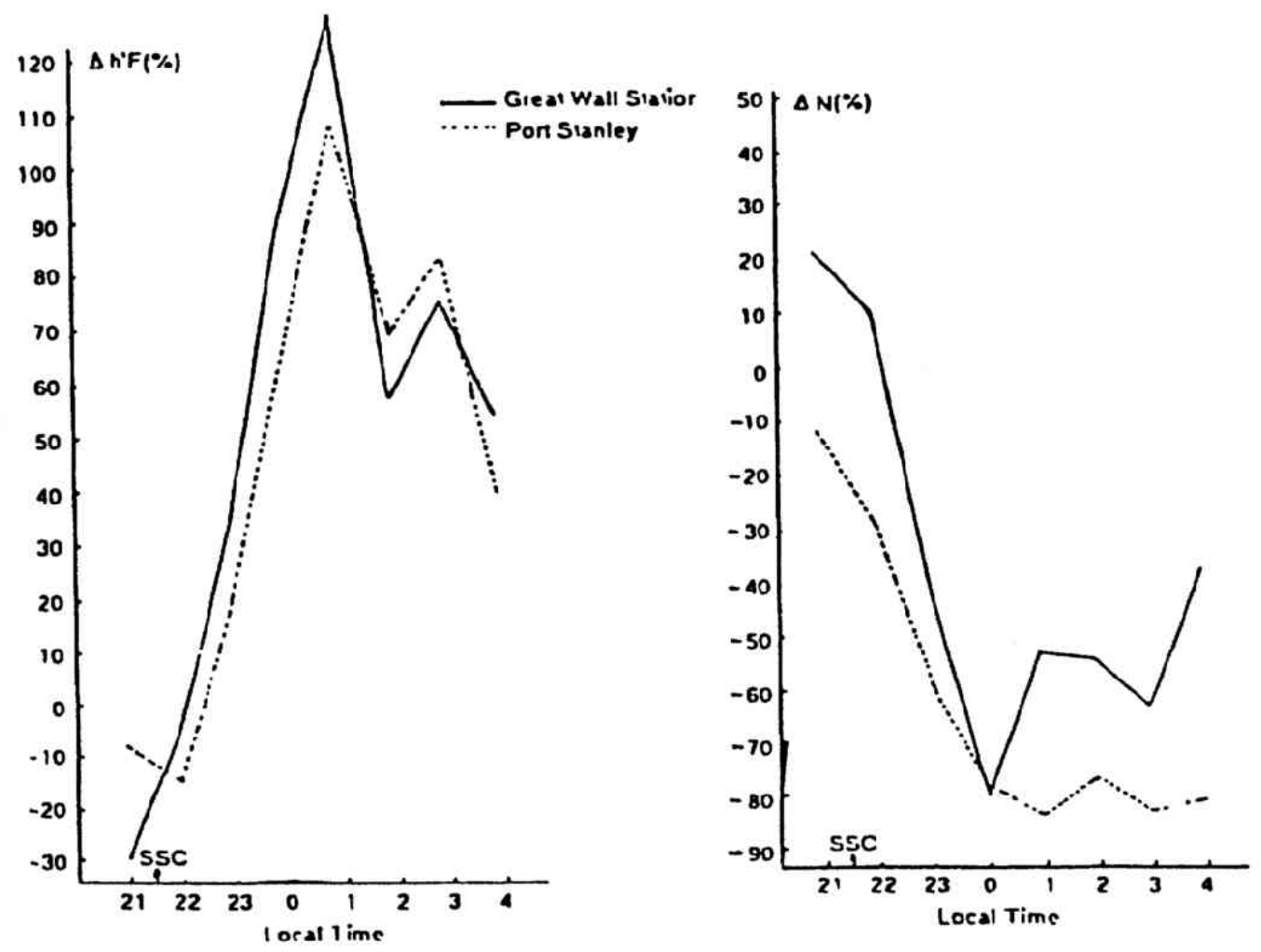

Fig. 2. Variations in the minimum virtual height of $F$ layer $\left(h^{\prime} F\right)$ and peak electron density of $F$ layer $\left(N_{\max }\right)$ compared to the day before (a magnetically quiet day) around the storm sudden commencement (SSC). The values on the day before were treated as the references. 


\section{Discussion}

Generally storm effects can be classified into positive effects and negative effects. A positive storm effect shows a rise of $f_{o} F_{2}$ above the normal value. On the other hand, a negative storm effect gives a depression of $f_{o} F_{2}$ below the normal value. The ionospheric effects of the March 13,1989 magnetic storm is a negative one. The onset of the magnetic storm is near local evening/midnight and in response to the magnetic activity negative ionospheric storm effects are seen almost immediately at Great Wall. Figure 2 shows that after the SSC $h^{\prime} F$ increased rapidly in association with a rapid decrease in peak electron density. During the period of three hours after SSC, the minimum virtual height of $F$ layer doubled to over $600 \mathrm{~km}$. An opposite decrease by $80 \%$ was observed in the peak electron density. These phenomena are perhaps due to a sudden equatorward motion and expansion of the trough region. During the later afternoon the trough steadily "moves" toward lower latitudes. The additional equatorward displacement and expansion caused by magnetic activity is superimposed on this local time variation. Thus it is well known that $h^{\prime} F_{2}$ increased dramatically in the trough region (Bowman, 1969). It should be pointed out from Fig. 2 that this negative effect took place almost simultaneously at both Great Wall and Port Stanley.

Although most of $F$ traces were missing because of severe absorption during the main phase of the storm, depletions in $f_{o} F_{2}$ were still observed sometimes and lasted till $2000 \mathrm{LT}$ on March 15 . The negative ionospheric storm effects during the main phase is probably caused by changes in the thermospheric neutral gas composition (Prolss et al., 1991). The precipitation flux and the resulting heating can produce changes in neutral composition. The prominent features of these changes are an increase of the molecular nitrogen and oxygen densities and a concurrent decrease of the atomic oxygen density. The increase in
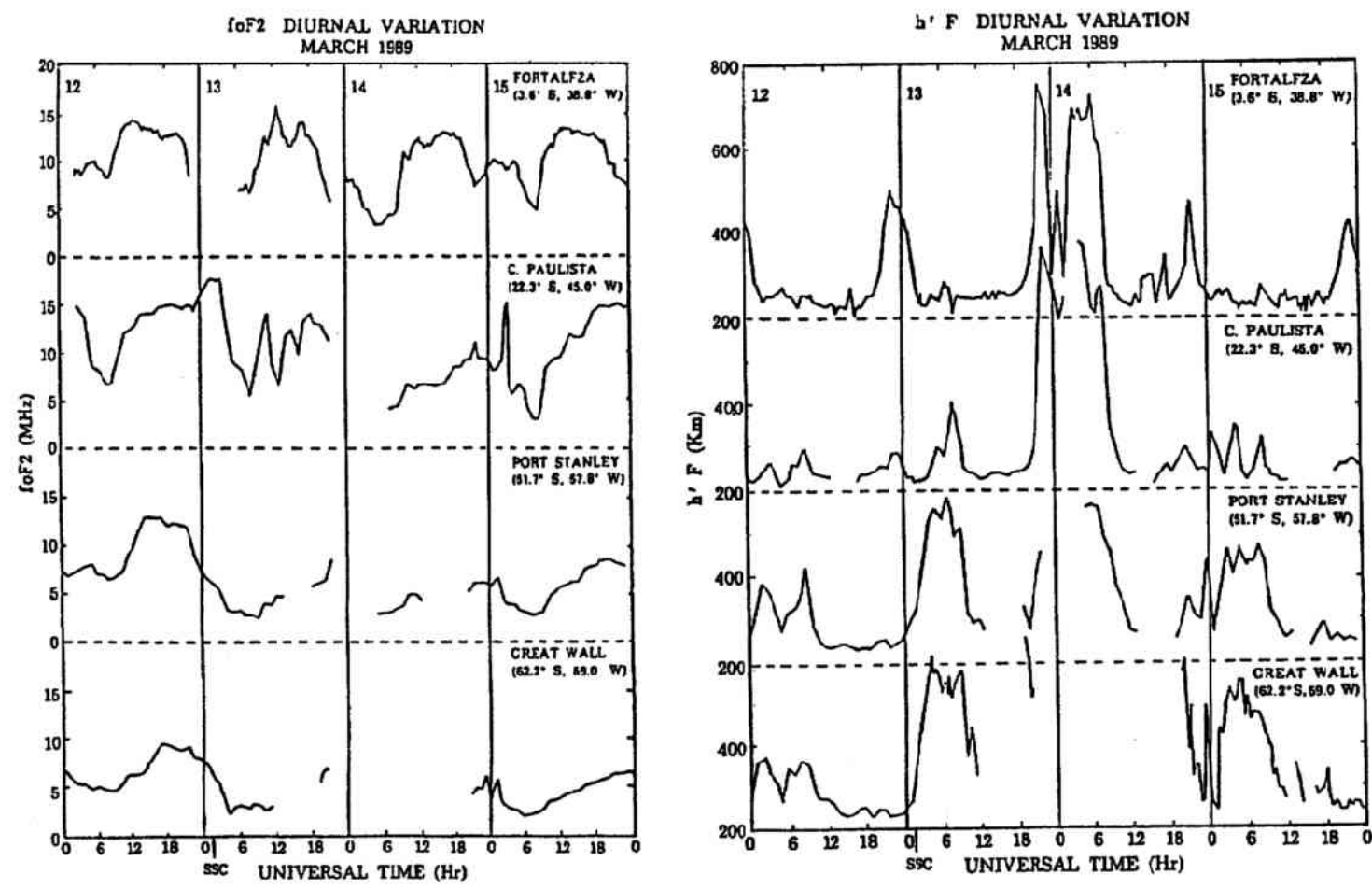

Fig. 3. The variations of $f_{o} F_{2}$ and $h^{\prime} F$ from four ionosonde stations in the same longitude sector, respectively. They are Fortaleza $\left(3.6^{\circ} \mathrm{S}, 38.3^{\circ} \mathrm{W}\right)$, Cachoeira Paulista $\left(22.3^{\circ} \mathrm{S}, 45.0^{\circ} \mathrm{W}\right)$, Port Stanley $\left(51.7^{\circ} \mathrm{S}, 57.8^{\circ} \mathrm{W}\right)$ and Great Wall, all in the local midnight sector. 
$\mathrm{O}_{2} / \mathrm{O}$ and $\mathrm{N}_{2} / \mathrm{O}$ ratio will lead to a decrease of $F$ layer ionization density (Prolss and Vonzahn, 1974; Chandra and Spencer, 1976; Forbes, 1989).

Figure 3 shows the variations in $f_{o} F_{2}$ and $h^{\prime} F_{2}$ from four ionosonde stations in the same longitude sector. They are Great Wall, Port Stanley $\left(51.7^{\circ} \mathrm{S}, 57.8^{\circ} \mathrm{W}\right)$, Cachoeira Paulista $\left(22.3^{\circ} \mathrm{S}, 45.0^{\circ} \mathrm{W}\right)$ and Fortaleza $\left(3.6^{\circ} \mathrm{S}, 38.8^{\circ} \mathrm{W}\right)$, all in the local midnight sector. From Fig. 3 we can see that just after the SSC, $f_{o} F_{2}$ decreased and $h^{\prime} F$ increased rapidly, these phenomena were less pronounced for stations of lower latitude. The variations of $f_{o} F_{2}$ is in opposite sense at Fortaleza and Cachoeira Paulista after around 1145 UT on March 13, giving the evidence for the penetration of a westward electric field to low and equatorial latitudes (Batista et al., 1991). Figure 3 also shows that the higher the station's latitude is, the more severe absorptions occur and the longer the absorptions last. A few hours following the SSC the diurnal minimum in $f_{o} F_{2}$ of all stations dropped down to a value much below the usual minimum with a simultaneous rise in $h^{\prime} F$. The low diurnal minimum continued into the second day with a recovery occurring on the third day. The depression of diurnal peak in $f_{0} F_{2}$ lasted for three days at sub-auroral and high mid-latitudes as represented by Great Wall and Port Stanley, two days at mid-latitudes as represented by Cachoeira Paulista, and little if any at the equator (Fortaleza, $-8.5^{\circ}$ magnetic dip) (Yeh and Lin, 1992).

The effects of magnetic storms on $F$ region irregularities through spread $F$ on ionograms depend on the phases of the storms and the local time of the observing ionospheric intersection. A model of irregularity intensity during and after magnetic storm commencement is proposed (Aarons and Rodger, 1991). The occurrence of the spread $F$ demonstrated that the generation of irregularities during the magnetic storm at Great Wall could be explained by this model. In the sub-auroral regions during the injection phase, irregularities are the result of the convective electric field penetration to low latitudes due

DIURNAL VARIATIONS
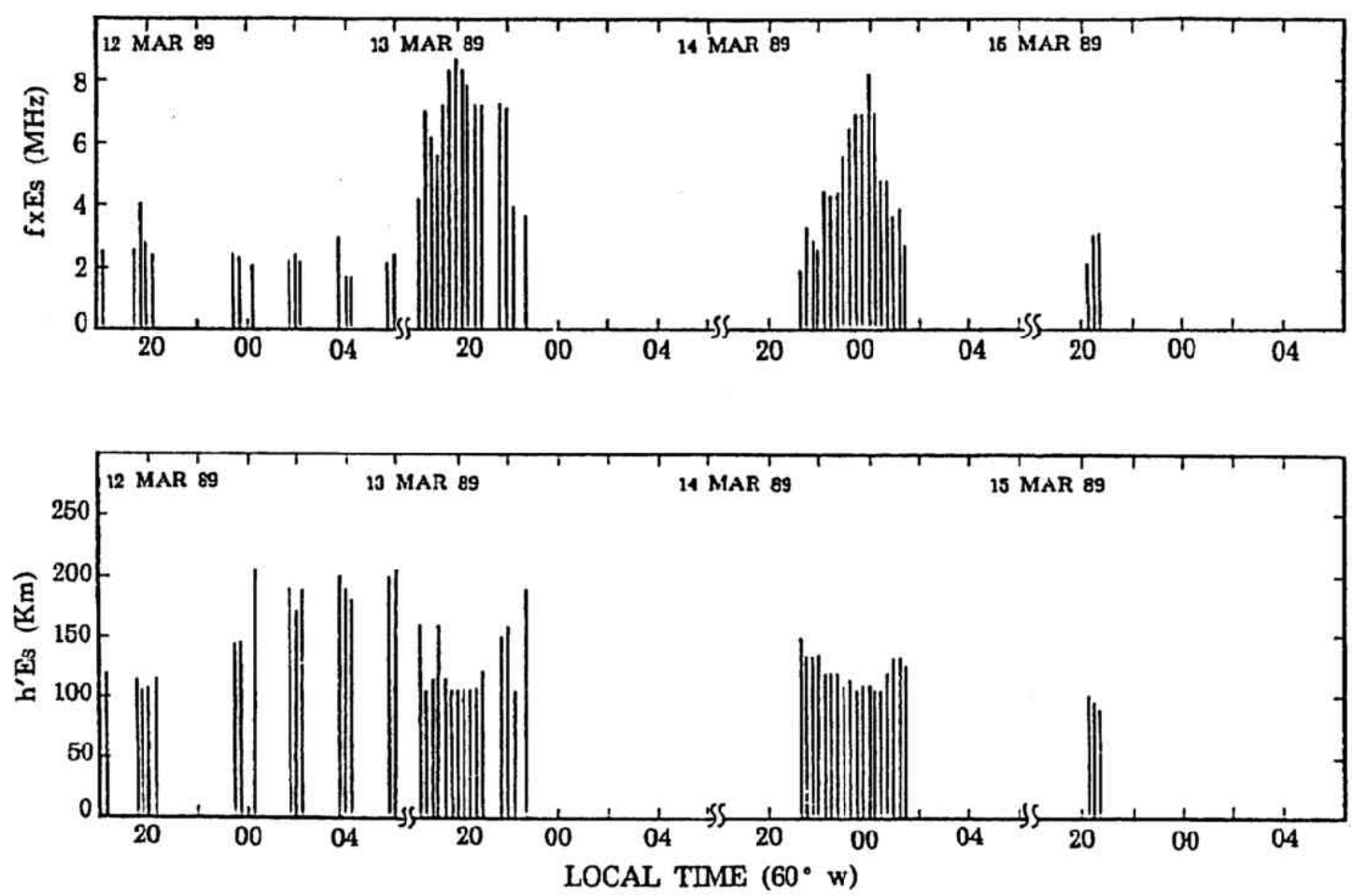

Fig. 4. Variations in the top frequency of the extraordinary wave component of Es traces $(f x E s)$ and the minimum virtual height of the $E s$ layer ( $\left.h^{\prime} E s\right)$. 
to the rate of motion of the equatorward edge of the auroral oval electric field. During the recovery phase, the ring current plays a leading role at sub-auroral latitudes. The ring current, which has acted as a reservoir for ionospheric and solar wind ions, decays. The irregularities at sub-auroral latitudes are produced.

Figure 4 shows that there were strong sporadic $E$ or night $E$ layers from $1830 \mathrm{LT}$ to $2230 \mathrm{LT}$ on March 13 and from 2130 LT on March 14 to 0130 LT on March 15 respectively, lasting about 4 hours each time. The highest $f x E s$ were $8.7 \mathrm{MHz}$ and $8.2 \mathrm{MHz}$ respectively, corresponding to a peak density around $7.5 \times 10^{5} \mathrm{el} \mathrm{cm}^{-3}$, much higher than the normal peak density of $E$ layer. At the beginning the peak density increased gradually and the height of the layer decreased from $150 \mathrm{~km}$. At the middle of the course the peak density reached its maximum of $7.5 \times 10^{5} \mathrm{el} \mathrm{cm}^{-3}$ and the layer went down to $100 \mathrm{~km}$. At the end the peak density decreased to $1 \times 10^{5} \mathrm{el} \mathrm{cm}^{-3}$ and the layer went up. On the fourth night, the night of March $15 / 16$, no strong sporadic $E$ or night $E$ appeared. At sub-auroral region, the occurrences of sporadic $E$ and night $E$ were associated closely with the energetic particle precipitations. These phenomena gave the evidence that only on the second and third nights after the SSC the flux of energetic particles impinged into low atmosphere, and the stronger the flux of energetic particles was, the lower atmosphere it impinged into.

We thank Prof. Cao Cong for running ionosonde and Mr. Yang Youhua for magnetometer at Great Wall, Antarctica.

\section{REFERENCES}

Aarons, J. and A. S. Rodger, The effects of electric field and ring current energy increases on $F$ layer irregularitics at auroral and subauroral latitudes, Radio Sci., 26, 1115-1129, 1991.

Batista, I. S., E. R. DePaula, M. A. Abdu, N. B. Trivedi, and M. E. Greenspan, Ionospheric effects of the 13 March 1989 magnetic storm at low and equatorial latitudes, J. Geophys. Res., 96, 13943-13952, 1991.

Bowman, G. G., Ionization troughs below the $F_{2}$-layer maximum, Planet. Space Sci., 17, 777-796, 1969.

Chandra, S. and N. W. Spencer, Thermospheric storms and related ionospheric effects, J. Geophys. Res., 81, 5018-5026, 1976.

Forbes, J. M., Evidence for the equatorward penetration of electric fields, winds, and compositional effects in Asia/Pacific sector during the September 17-24, 1984, ETS interval, J. Geophys. Res., 94, 16999-17007, 1989.

Hajkowicz, L. A., Global onset and propagation of large-scale traveling ionospheric disturbances as a result of the great storm of March 1989, Planet. Space Sci., 39(4), 583-593, 1991.

Huang, Y.N. and K. Cheng, Ionospheric disturbances at the equatorial anomaly crest region during March 1989 magnetic storms, J. Geophys. Res., 96, 13953-13965, 1991.

Lakshmi, D. R., B. C. N. Rao, A. R. Jain, M. K. Goel, and B. M. Reddy, Response of equatorial and low latitude $F$-region to the great magnetic storm of 13 March 1989, Ann.Geophys., 9, 286-290, 1991.

Prolss, G. W. and U. Von Zahn, Esro 4 gas analyzer results, 2. Direct measurements of changes in the neutral composition during an ionospheric storm, J. Geophys. Res., 79, 2535-2539, 1974.

Prolss, G. W., L. H. Brace, H. G. Mayr, G. R. Carignan, T. L. Killeen, and J. A. Klobuchar, Ionospheric storm effects at subauroral latitudes: A case study, J. Geophys. Res., 96, 1275-1288, 1991.

Yeh, K. C. and K. H. Lin, The global behavior of the March 1989 ionospheric storm, Can. J. Phys., 70, 532-543, 1992. 